\title{
Interactive comment on "Morphology of an arid landscape utilising synthetic-aperture radar (SAR) and differential interferometric SAR (DInSAR), southern Riyadh, Central Arabia" by Mohamed Daoudi et al.
}

\author{
Mohamed Daoudi et al. \\ mdaoudi@kau.edu.sa \\ Received and published: 15 February 2021
}

\section{Dear Associate Editor}

First of all, we would like to thank the first reviewer for considering revision, and for his/her valueble comments. Also we are grateful to his appreciation of our effort in applying a compolex techniques in the field of active remote sensing. Regarding general comment 1, we think that the introduction can be separated as he suggested into two sections to put the study area section immediatly as after introduction. General 
comment 2, We have added more information about the software. General comment 3 , The discussion has been improved to show linkage between results and objectives.

Specific comment 1, is applicable and was changed in the revised manuscript Specific comment 2, we have checked the statement retyped a revised one. Specific comment 3, also the statement was revised Specific comment 4, is also been restated to show the contribution of this study. Specific comment 5, more details on the software GAMMA is added with reference Specific comment 6 and 9, we put the scale and coordinates of the images in the figure, and removed the minimized image and a larger image. Specific comment 7, the equastion was revised Specific comment 8, the intrductory statement was revised for taking off the misunderstanding, occured in that section. Specific comment 10, we II mentionhow it was estimated: from city limits difference between 1996 and 2008. Specific comment 11, the world substracted has been changed Specific comments 12, the entire discussion section is revised to be linked with other parts of the manuscript. The references mentioned in this comment is removed.

All changes will be shown in red color.

\section{Regards}

Interactive comment on Geosci. Instrum. Method. Data Syst. Discuss., https://doi.org/10.5194/gi-2020-32, 2020. 